\title{
Modeling Tuberculosis in Nonhuman Primates
}

\author{
Charles A. Scanga and JoAnne L. Flynn \\ Department of Microbiology and Molecular Genetics, University of Pittsburgh School of Medicine, \\ Pittsburgh, Pennsylvania 15261 \\ Correspondence: joanne@pitt.edu
}

Nonhuman primates have emerged as an excellent model of human tuberculosis, in large part because they recapitulate the full spectrum of infection outcome and pathology seen in humans. Several variables inherent to the nonhuman primate models of tuberculosis are discussed in this review, including the monkey species, Mycobacterium tuberculosis strains, and routes of infection, all of which can influence the model to be chosen for various studies. New technologies for studying the microbiology, immunology, and pathogenesis of tuberculosis in nonhuman primates have greatly expanded the capabilities of this model for basic and translational studies, including the development and testing of new treatment and prevention strategies for tuberculosis.

Exposure to Mycobacterium tuberculosis reEsults in a wide range of outcomes, from clearance of the pathogen without establishment of infection, to active tuberculosis (TB), to asymptomatic, latent infection. Latent TB is a complex infection state (Barry et al. 2009; Lin and Flynn 2010) that can reactivate and cause active TB. TB has diverse clinical presentations and can arise in practically any organ system, although the lungs are most commonly involved. Granulomas are the pathologic hallmark of TB and primarily responsible for the immunopathology of TB. They are classically described as organized inflammatory structures consisting of a necrotic core containing both infected and uninfected macrophages as well as multinucleated giant cells (Langerhans cells), surrounded by B and $\mathrm{T}$ lymphocytes, encased by a rim of fibroblasts. In reality, lesions in active $\mathrm{TB}$ can vary widely, even within the same patient, and can be necrotic (caseous), nonnecrotizing, or suppura- tive (Flynn and Klein 2011). Tuberculous pneumonia, consolidations, and cavities may also be present. Similarly, lesions associated with latent TB may be caseous, fibrocalcific, sclerotic, or mineralized.

Existing antituberculous drugs require 6- to 9-month regimens and drug resistance increasingly limits their effectiveness. The vaccine against TB, Mycobacterium bovis Bacillus Calmette-Guérin (BCG), was developed nearly 100 years ago and has only limited efficacy (Andersen and Doherty 2005). New antibiotics, vaccines, and novel therapeutics are needed urgently. Developing these requires a model system that recapitulates the complexity of human TB. The ideal animal model would include (1) susceptibility to the same $M$. tuberculosis strains that cause human disease; (2) similar disease presentations and complex lesional histopathology; (3) recapitulation of the entire spectrum of possible infection outcomes; (4) latent TB states

Editors: Stefan H.E. Kaufmann, Eric J. Rubin, and Alimuddin Zumla

Additional Perspectives on Tuberculosis available at www.perspectivesinmedicine.org

Copyright (C) 2014 Cold Spring Harbor Laboratory Press; all rights reserved; doi: 101101/cshperspect.a018564

Cite this article as Cold Spring Harb Perspect Med 2014;4:a018564 
that can be reactivated by the same triggers as in humans; (5) immunologic similarity to humans, allowing for cross-reactive immunologic tools and vaccine responses predictive of those in humans; (6) outbred animals reflecting human genetic diversity; and, last, (6) physiologic and metabolic similarity to humans, facilitating translational drug development. Numerous animal models of TB exist, each possessing unique advantages and disadvantages. However, only the nonhuman primate (NHP) model shows all of the features listed above (Flynn et al. 2008). NHPs have been used in TB research for decades and have become a unique and powerful research tool that recapitulates all important aspects of human disease.

\section{HISTORICAL USE OF NHPs IN TB RESEARCH}

NHPs are susceptible to natural $M$. tuberculosis infection. Outbreaks in both feral (Keet et al. 2000; Michel et al. 2013) and captive (Schroeder 1938; Benson et al. 1955; Mayhall et al. 1981; Fourie and Odendaal 1983; Shin et al. 1995; Panarella and Bimes 2010; Payne et al. 2011) colonies have been reported. All NHP species are considered potentially susceptible to $M$. $t u$ berculosis infection (Good 1984), with a general susceptibility hierarchy of Old World species (most susceptible), followed by apes, and New World monkeys (least susceptible) (Montali et al. 2001).

NHPs were first used for TB research in pioneering work by Leon Schmidt who used rhesus macaques (Macaca mulatta) to study antituberclous drugs (Schmidt 1956, 1966; Schmidt et al. 1959). After intratracheal instillation of $10^{2}-10^{3}$ colony-forming units (CFU) M. tuberculosis 5159, all macaques succumbed to active TB with caseous granulomas and cavitary disease in the lungs. This work established the rhesus macaque as susceptible to even moderately low doses of M. tuberculosis. Robert Good extended the use of this rhesus model to show that BCG conferred marked protection from $M$. tuberculosis challenge (Good 1968). Barclay et al. (1970) further refined the use of rhesus for vaccine research by introducing the aerosol infection route and by using the virulent $\mathrm{H} 37 \mathrm{Rv}$
M. tuberculosis strain still commonly used in TB research laboratories. Unlike the extensive and confluent pulmonary disease resulting from direct intratracheal instillation of $M$. $t u$ berculosis reported by both Schmidt and Good (Schmidt 1956; Good 1968), aerogenic infection of rhesus macaques with a low-dose inoculum $(<50 \mathrm{CFU})$ resulted in discrete granulomas, the initial number of which approximated the calculated infectious dose (Barclay et al. 1970). Aerogenic infection still resulted in progressive TB that was proportional in rate to the infective dose and BCG vaccination afforded striking protection from this challenge. Notably, tuberculous hilar lymphadenopathy was a much more prominent feature of disease initiated by aerosol than by intratracheal instillation. Over the next few years, low-dose, aerogenic challenge of rhesus macaques with virulent $M$. tuberculosis remained the NHP model of choice for vaccine studies (Baram et al. 1971; Ribi et al. 1971; Barclay et al. 1973; Janicki et al. 1973; Chaparas et al. 1975). Perhaps because of reduced availability of rhesus macaques for experimentation and waning interest in TB research, no TB studies using monkeys appeared in the literature from 1975 until 1996. The emergence of the human immunodeficiency virus (HIV) pandemic reinvigorated interest in modeling infectious diseases in NHPs, especially the use of macaques experimentally infected with simian immunodeficiency virus (SIV). The increasing prevalence of AIDS resulted in a resurgence of TB in many countries (Corbett et al. 2003) and renewed interest in TB research. In 1996, Walsh et al. established a novel NHP model of TB using cynomolgus macaques (Macaca fasicularis) (Walsh et al. 1996), heralding the beginning of a new era that has witnessed a tremendous increase in the use of NHPs to model TB.

\section{NHP SPECIES}

From Schmidt's initial study in 1956 (Schmidt 1956) until the 1990s, rhesus macaques exclusively were used for TB research. Seeking to take advantage of the ready supply of captive-bred cynomolgus macaques in the Philippines, Marcus Horwitz initiated a study to evaluate this 
species as a model of human TB (Walsh et al. 1996). Animals were infected intratracheally with a wide dose range of Erdman strain $M$. tuberculosis $\left(10^{1}-10^{5} \mathrm{CFU}\right)$ and monitored for up to 7 months. The outcome was clearly dosedependent. Macaques receiving high infectious doses $\left(10^{5}\right.$ and $\left.10^{4} \mathrm{CFU}\right)$ succumbed to $\mathrm{TB}$ after 7-13 wk with extensive bilateral tuberculous pneumonia with abundant necrosis and extrapulmonary manifestations such as ocular $\mathrm{TB}$, meningitis, and spondylitis (Pott's disease). Animals receiving a moderate infectious dose $\left(10^{3}\right.$ $\mathrm{CFU}$ ) developed more slowly progressive disease that caused mortality by $14-24$ wk. Pulmonary pathology was still widespread but showed less necrosis and more cellular infiltration, but there was less extrapulmonary disease. The disease in macaques infected with low doses of M. tuberculosis $\left(<10^{2} \mathrm{CFU}\right)$ progressed even more slowly and these animals survived $\geq 19$ wk postinfection. Granulomas arising in these animals were much smaller and densely cellular, resembling lesions typical of human TB. Most strikingly, three of the eight macaques receiving $<10^{2}$ CFU did not show any clinical or radiographic signs of disease after 7 mo, despite immunologically confirmed infection. Necropsy revealed disease mostly confined to the lungs. This report (Walsh et al. 1996) of subclinical disease in three NHPs infected with a low dose of M. tuberculosis revealed the potential of NHPs to model both latent and active TB. This concept was further developed in a seminal study in which 17 cynomolgus macaques were infected with $\sim 25$ CFU M. tuberculosis Erdman by bronchoscopic instillation (Capuano et al. 2003). Despite being infected with the same dose, the animals showed a range of outcomes from rapidly progressive $\mathrm{TB}$ to latent $\mathrm{TB}$ that, in some animals, was stably maintained for $>20$ mo. A wide spectrum of granuloma morphologies was noted from caseous, to solid cellular, to fibrocalcific that recapitulated the range of histopathology in human TB (Fig. 1). These studies further established that cynomolgus macaques could manifest the various TB disease states seen in humans, with $\sim 40 \%$ of animals developing active TB and $60 \%$ developing latent infection. Lin et al. (2009) identified clinical pa-

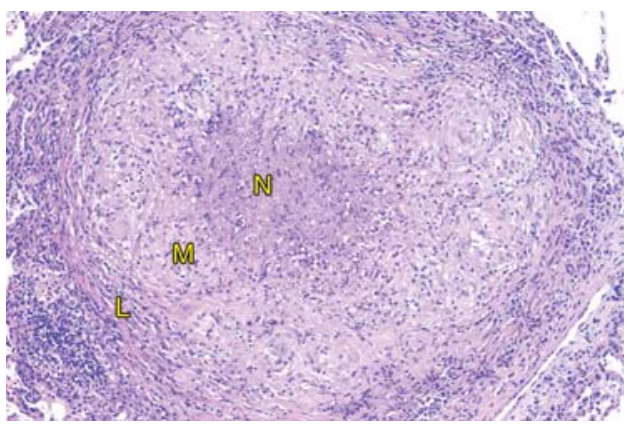

Figure 1. Pulmonary granuloma from a cynomolgus macaque 20 wk after Mycobacterium tuberculosis infection showing striking similarity to classical TB histopathology in humans. A macrophage-enriched zone $(\mathrm{M})$ surrounds a central area of necrosis $(\mathrm{N})$ with an outer lymphocytic/fibrocytic cuff (L). Original magnification $10 \times$. (Courtesy of Dr. Edwin Klein, University of Pittsburgh.)

rameters indicative of active disease, such as weight loss, abnormal chest X-ray (CXR), culture-positive gastric aspirates, and elevated erythrocyte sedimentation rate (ESR). Monkeys with latent TB therefore could be identified as those animals that presented none of these clinical signs within 6 mo postinfection (Lin et al. 2009). These clinical classifications were confirmed by gross pathology and bacterial load scoring at necropsy. This "low-dose inoculum" cynomolgus model of TB was used by our group to study both acute (up to $6 \mathrm{wk}$ postinfection) and chronic ( $>1 \mathrm{yr}$ postinfection) M. tuberculosis infection (Lin et al. 2006, 2009). Cynomolgus macaques therefore can model all manifestations of the entire spectrum of infection outcomes in humans (Table 1).

Cynomolgus macaques used for research typically come from large colonies in Asia or Indonesia and show substantial genetic diversity. Cynomolgus macaques from the isolated island of Mauritius, on the other hand, have much less genetic diversity (Krebs et al. 2005), and their MHC alleles are limited and well-defined. This makes Mauritian cynomolgus macaques ideal for developing MHC:peptide tetramers that can be used to identify, track, and isolate antigen-specific $\mathrm{T}$ cells, a feature that has been exploited in SIV research (Burwitz et al. 
C.A. Scanga and J.L. Flynn

Table 1. Summary of nonhuman primate species used to model tuberculosis

\begin{tabular}{|c|c|c|}
\hline Monkey species & Advantages & Disadvantages \\
\hline $\begin{array}{l}\text { Cynomolgus macaque } \\
\text { (Macaca fascicularis) }\end{array}$ & $\begin{array}{l}\text { Best represents the entire spectrum } \\
\quad \text { of human TB } \\
\text { Can develop either latent or active TB } \\
\text { Well-developed immunologic reagents } \\
\text { Relatively resistant to } M t b \\
\text { Readily available }\end{array}$ & $\begin{array}{l}\text { Expensive to purchase and to } \\
\text { maintain } \\
\text { Large size: limits housing } \\
\text { capacity, requires more } \\
\text { product for drug studies }\end{array}$ \\
\hline $\begin{array}{l}\text { Rhesus macaque } \\
\text { (Macaca mulatta) }\end{array}$ & $\begin{array}{l}\text { Recapitulates many aspects of human TB } \\
\text { Relatively susceptible to } M t b \\
\text { Well-developed immunologic reagents }\end{array}$ & $\begin{array}{l}\text { Expensive and large } \\
\text { More limited availability }\end{array}$ \\
\hline $\begin{array}{l}\text { Common marmoset } \\
\text { (Callithrix jacchus) }\end{array}$ & $\begin{array}{l}\text { Recapitulates many aspects of human TB } \\
\text { Much smaller than macaques, increasing } \\
\text { housing capacity and decreasing amount } \\
\text { of test substance needed for drug studies } \\
\text { Easily group-housed } \\
\text { Frequent dizygotic twinning }\end{array}$ & $\begin{array}{l}\text { Limited number of suppliers } \\
\text { More limited immunologic } \\
\text { reagents } \\
\text { Smaller size limits biological } \\
\text { sampling frequency/amount }\end{array}$ \\
\hline
\end{tabular}

2009; Budde et al. 2012). Although there are no published reports yet of experimental $\mathrm{TB}$ in Mauritian cynomolgus macaques, these animals have the potential to expand our repertoire of tetrameric immunologic probes targeting mycobacteria-specific $\mathrm{T}$ cells from the single tetramer reported so far (Wei et al. 2009).

Although several studies (Walsh et al. 1996; Capuano et al. 2003; Lin et al. 2009) firmly establish that cynomolgus macaques are relatively resistant to $M$. tuberculosis and can model the entire spectrum of human TB including latent disease, rhesus macaques appear more susceptible. Early studies showed that even relatively low doses of $M$. tuberculosis caused progressive, fatal TB in rhesus monkeys (Good 1968; Ribi et al. 1971). In a dose-response study in which rhesus macaques were infected intratracheally with 50, 200, 500, or 3000 CFU M. tuberculosis $\mathrm{H} 37 \mathrm{Rv}$, all doses resulted in active TB with disease progression rate correlated with inoculum size (Zhang et al. 2011). Three studies have directly compared the susceptibility to TB in rhesus and cynomolgus macaques. Motzel et al. infected cynomolgus macaques $(n=6)$, rhesus macaques $(n=6)$, and vervets (Chlorocebus pygerythrus) $(n=5)$ using $100 \mathrm{CFU}$ of M. tuberculosis Erdman injected intrathecally. Based on survival times, vervets were by far most susceptible, with rhesus and, especially, cynomolgus macaques showing more resistance (Motzel et al. 2003). In another direct comparison study, both rhesus and cynomolgus macaques were intratracheally infected with $3000 \mathrm{CFU}$ M. tuberculosis (Erdman strain) and the rhesus showed more extensive lung disease and extrapulmonary spread (Langermans et al. 2001). More recently, Sharpe et al. (2009) showed greater susceptibility in rhesus macaques compared with cynomolgus macaques following lowdose (30-75-CFU) aerosol infection with $M$. tuberculosis Erdman. In contrast, several studies show resistance in rhesus macaques. Gormus et al. (2004) reported subclinical TB in rhesus monkeys infected with the $\mathrm{H} 37 \mathrm{Rv}$ strain of M. tuberculosis, whereas animals infected with strain Erdman developed progressive TB. Latent TB was reported in rhesus macaques infected with the less virulent $M$. tuberculosis strain CDC1551 (Mehra et al. 2011). Rhesus macaques used for research are of either Chinese or Indian origin and substantial genetic differences exist between the two subspecies (Yan et al. 2011). Interestingly, the studies reporting latent $\mathrm{TB}$ in rhesus macaques used animals of Indian origin (Safi et al. 2003; Gormus et al. 2004; Mehra et al. 2011), whereas the study showing susceptibility of rhesus macaques to low-dose inocula used animals from China (Zhang et al. 2011), suggesting distinct resistance patterns between Chinese and Indian rhesus, although a direct comparison has not been reported. Overall, ex- 
perimental $\mathrm{TB}$ in rhesus macaques resembles many key aspects of human disease, but it is widely considered to reflect TB in susceptible individuals because of the overwhelming tendency of this species to develop active TB regardless of the inoculating dose (Table 1).

Recently, a new NHP model of TB using the common marmoset (Callithrix jacchus) was described (Via et al. 2013). Marmosets are New World monkeys that are much smaller (300$500 \mathrm{~g})$ than Old World primates such as macaques (2 to more than $10 \mathrm{~kg}$ ). Via et al. tested the susceptibility of marmosets to mycobacteria of differing virulence: the virulent K04 clinical isolate and Erdman strain, the less virulent $M$. tuberculosis strain CDC1551, and the M. tuberculosis complex member M. africanum. Lowdose aerogenic infection with all mycobacterial strains resulted in fulminant TB that progressed at a rate proportional to the virulence of the strain used (Via et al. 2013). Intratracheal infection with strain Erdman also resulted in extensive disease. Marmosets thus display a striking susceptibility to mycobacteria and, like larger NHP species, recapitulate some of the clinicopathologic manifestations of human TB. An advantage of marmosets, in addition to their small size, is that they have a high incidence of dizygotic twinning. Because a number of crossreactive immunologic reagents are also available (Brok et al. 2001), elegant immunologic studies are possible in this novel small NHP model of TB.

\section{EFFECT OF INOCULUM STRAIN, DOSE, AND ROUTE}

The mycobacterial strain, inoculum dose, and infection route can greatly affect the outcome of NHP infection. Different M. tuberculosis strains can show distinct virulence characteristics in mice (Caceres et al. 2012), guinea pigs (Palanisamy et al. 2008), and rabbits (Tsenova et al. 2005). Head-to-head comparisons of bacterial strain virulence have not been performed in NHPs. Thus, inferences must be made by comparing outcomes reported in separate NHP studies, which frequently are performed by different researchers, at different times, using dif- ferent strain isolates, doses, and infection routes. Nonetheless, some conclusions may be drawn from the literature.

Different strains of $M$. tuberculosis can display distinct virulence patterns in NHPs, as in other animal species (Tsenova et al. 2005; Palanisamy et al. 2008; Caceres et al. 2012). CDC1551, a clinical isolate of M. tuberculosis that is highly immunogenic (Manca et al. 1999), appears to be less virulent than other M. tuberculosis strains in some animal models (Tsenova et al. 2005) but not others (Palanisamy et al. 2008). When used to infect 12 rhesus macaques, CDC1551 (500 CFU, aerosol) resulted in early, active TB in only one animal, whereas the other 11 developed subclinical infection (Mehra et al. 2011). Conversely, marmosets appear quite susceptible to low dose $(<25 \mathrm{CFU})$ aerosolized CDC1551, succumbing to the infection within 70 days (Via et al. 2013).

The majority of TB studies in NHPs were performed using the Erdman strain (Walsh et al. 1996; Langermans et al. 2001; Capuano et al. 2003; Chen et al. 2009; Lin et al. 2009; Sharpe et al. 2009, 2010; Lin et al. 2012c, 2014), although several used H37Rv (Shen et al. 2002b; Gormus et al. 2004; Zhang et al. 2011; Rayner et al. 2013). Although Erdman is generally thought to be more virulent in NHPs, this might not be so clear-cut. The most powerful piece of evidence for this belief is the report by Gormus et al., in which rhesus macaques infected intrabronchially with $\geq 10 \mathrm{CFU}$ of $M$. tuberculosis Erdman all developed active TB, whereas infection with $\leq 200 \mathrm{CFU}$ of $M$. tuberculosis H37Rv resulted in subclinical disease in all animals (Gormus et al. 2004). In another study, six rhesus macaques chronically infected with SIV were challenged with $M$. tuberculosis $\mathrm{H} 37 \mathrm{Rv}$ (200 CFU) and half the animals developed latent $\mathrm{TB}$, despite their presumed immunodeficiency (Safi et al. 2003). The H37Rv strain can be quite virulent for NHPs as well. Not surprisingly, high-dose ( $\geq 1000 \mathrm{CFU}) \mathrm{H} 37 \mathrm{Rv}$ uniformly results in active $\mathrm{TB}$ in rhesus macaques (Lewinsohn et al. 2006; Sugawara et al. 2009). When delivered by aerosol to rhesus macaques, 400-500 CFU of the H37Rv strain caused fatal TB in 4-6 wk (Shen et al. 2002b). However, in 
contrast to Gormus et al. (2004) and Safi et al. (2003), two reports showed that rhesus macaques infected with as few as $50 \mathrm{CFU}$ of M. tuberculosis H37Rv all developed active disease (Zhang et al. 2011; Min et al. 2013). The reports of latent or subclinical TB in rhesus macaques infected with $\mathrm{H} 37 \mathrm{Rv}$ may be related more to the geographic source of the animals and less to the virulence of the infecting strain because both reports of limited disease following $M$. tuberculosis $\mathrm{H} 37 \mathrm{Rv}$ infection used rhesus of Indian, rather than Chinese, origin (Safi et al. 2003; Gormus et al. 2004). It is also possible that different isolates or preparations of the same strain have varying levels of virulence.

Although the Erdman strain of M. tuberculosis appears more virulent in NHPs because of its ability to cause progressive TB in both rhesus (Langermans et al. 2001; Gormus et al. 2004; Sharpe et al. 2009, 2010) and cynomolgus (Walsh et al. 1996; Langermans et al. 2001; Capuano et al. 2003; Sharpe et al. 2009; Lin et al. 2010, 2012b) macaques, low doses (25 CFU) of Erdman in cynomolgus macaques lead to latent TB in half the monkeys (Lin et al. 2009, 2010, 2012b,c; Diedrich et al. 2010; Mattila et al. 2011). When larger inocula (250-500 CFU) of the same Erdman strain were similarly delivered to cynomolgus macaques, all progressed to active TB (Lin et al. 2012b; Chen et al. 2013). Thus, the outcome of infection with M. tuberculosis Erdman in cynomolgus monkeys is dose-dependent, as first shown by Walsh et al. (1996). A similar relationship between inoculum size and disease progression following M. tuberculosis $\mathrm{H} 37 \mathrm{Rv}$ infection in rhesus macaques also exists (Zhang et al. 2011).

The method used to infect NHPs also plays a role in determining disease progression and outcome. The two most commonly used routes of infection for NHP studies of TB are intraairway instillation and inhalation of aerosolized bacilli. The earliest reports of experimental $M$. tuberculosis infection of NHPs used intratracheal instillation (Schmidt 1956, 1966; Schmidt et al. 1959), as did several more recent studies (Walsh et al. 1996; Langermans et al. 2001). This protocol was improved on by introducing a flexible fiber-optic bronchoscope (Capuano et al.
2003), and bronchoscopic instillation has become the standard method for intra-airway inoculation of M. tuberculosis. The bronchoscope facilitates precise delivery of inocula directly into targeted lung segments using direct fiberoptic visualization. The inoculum volume and concentration can be measured to accurately calculate the infecting dose. Following lowdose bronchoscopic infection, granulomas appear first in the lungs 3-4 wk postinfection and then in the draining hilar lymph nodes by $\sim 5$ wk (Lin et al. 2006). Although initially uniformly caseous (Lin et al. 2006), these granulomas eventually develop into a wide spectrum of lesion types (Lin et al. 2009). However, even though monkeys infected intrabronchially can show the entire spectrum of TB seen in humans (Capuano et al. 2003; Lin et al. 2009), this route does not reflect the natural transmission of TB and bypasses host defenses of the upper respiratory tract.

Because infectious aerosols transmit TB, experimental infection by aerosolized bacteria is thought to best reflect the natural route of $M$. tuberculosis transmission. Early vaccine studies used aerogenic infection (Barclay et al. 1970, 1973; Baram et al. 1971; Ribi et al. 1971; Janicki et al. 1973; Chaparas et al. 1975; Shen et al. 2002b). Following aerosol infection of rhesus macaques with M. tuberculosis H37Rv, lesions appear in the lungs and hilar lymph nodes within $3 \mathrm{wk}$ postinfection and show varied histopathologic appearance (Rayner et al. 2013). Sharpe et al. recently sought to further refine the aerosol infection route (Sharpe et al. 2010). Rhesus macaques of Indian origin were exposed to $\sim 50$ CFU M. tuberculosis Erdman, and clinical (body weight, ESR, CXR) and postmortem parameters (gross pathology, lung pathology, bacterial load) were assessed. All animals progressed to active TB despite substantial animal-to-animal variation, especially in terms of survival times that ranged from 6 to $48 \mathrm{wk}$. Much of the variability is likely due to genetic differences between animals, but at least some can be attributed to the many variables involved in preparing and delivering aerogenic inocula to individual animals (Clark et al. 2011). Coupling aerosol infection with real-time plethysmogra- 
phy may reduce variation (Sharpe et al. 2009). This infection route also requires larger, more specialized equipment than intrabronchial instillation. Although bronchoscopic instillation does bypass innate defenses of the upper respiratory tract, aerosol infection typically delivers monodispersed bacteria in uniform droplets $\sim 2 \mu \mathrm{M}$ in diameter. Although this approximates the droplet size considered most infectious in the aerosol cloud emanating from coughing TB patients (Fennelly et al. 2012), the infectious nuclei generated by a laboratory nebulizer differ physiochemically from the complex aerosols generated by the cough of a tuberculous person and may interact differently with the innate immune system within the airway. Although a direct comparison between aerosol and bronchoscopic infection has not been performed, some evidence suggests that the aerosol route is more virulent. Aerosol infection of cynomolgus macaques with 30-40CFU M. tuberculosis Erdman resulted in varied disease progression rates but without evidence of true latent TB within the 12-wk follow-up period (Sharpe et al. 2009). In a more limited study, aerogenic infection of cynomolgus macaques with $<20 \mathrm{CFU}$ strain Erdman resulted in progressive disease in all four animals (J Flynn, C Scanga, and P Lin, unpubl.).

Thus, the choice of M. tuberculosis strain, size of the inoculating dose, and route of infection can all affect the outcome of experimental TB in NHPs. All these parameters must be carefully considered when planning studies or evaluating results.

\section{IN VIVO IMAGING OF NHPs INFECTED WITH M. tuberculosis}

Small animal models of TB that show minimal animal-to-animal variability (e.g., mice, guinea pigs, rabbits) provide the opportunity to kill small numbers of animals at various time points following infection to understand dynamic processes. This approach is less feasible with NHPs, which are much more variable and resource-intensive. A distinct advantage of low-dose infection of cynomolgus macaques is that different disease states (e.g., active or latent TB) can de- velop. When animals are killed at early time points, there is no way to know a priori if that animal was destined to develop active or latent TB. In vivo imaging offers a way to monitor disease progression over time within the same animal. Beginning with some of the earliest studies (Schmidt 1966), CXR is often used to monitor TB progression (Verreck et al. 2009). However, the resolution of conventional CXR is poor and cannot detect subtle changes in pulmonary lesions. A large step forward was made in 2006 when computed tomography (CT) was used to serially assess disease development in rhesus macaques following high-dose $M$. tuberculosis infection (Lewinsohn et al. 2006). CT offers both a 10-fold increase in spatial resolution and the ability to assess extrapulmonary organs. Magnetic resonance imaging (MRI), which is especially good at producing high-resolution images of soft tissue, has also been used to visualize lung lesion distribution (Sharpe et al. 2009, 2010; Rayner et al. 2013) and can be combined with stereology to quantitatively measure lung disease volume (Sharpe et al. 2009). Although MRI has the potential to serially follow disease development, it has so far been applied only ex vivo to excised and fixed lungs. The most recent imaging advance for $\mathrm{TB}$ studies combined high-resolution CT with positron emission tomography (PET) in living animals (Davis et al. 2009; Via et al. 2012). In PET imaging, ${ }^{18}$ F-fluorodeoxyglucose (FDG) injected intravenously is taken up and trapped within metabolically active cells (e.g., inflammatory cells within a granuloma). PET/CT imaging therefore conveys both the anatomic detail of $\mathrm{CT}$ as well as functional information (i.e., metabolic activity). PET/CT imaging has been used to follow TB progression in both marmosets (Via et al. 2013) and macaques (Lin et al. 2013, 2014). PET/CT imaging allows one to follow the appearance and distribution of individual granulomas; track changes in their size, shape, and metabolic activity over time; and then identify and analyze those individual lesions at necropsy. This allows one to correlate the in vivo evolution of lesions with ex vivo pathologic, immunologic, and bacteriologic parameters-all at the level of the individual granuloma. 


\section{APPLICATIONS OF THE NHP MODEL}

\section{New Insights into TB Pathogenesis}

Infection of cynomolgus macaques using lowdose ( 25-CFU) M. tuberculosis results in varied outcomes that closely mimic all forms of TB in humans (Capuano et al. 2003; Lin et al. 2009). This model system facilitates investigations of basic concepts of TB pathogenesis. Infection is initiated when bacilli enter the lungs, get taken up by phagocytes such as alveolar macrophages and dendritic cells, and begin to replicate. Bacilli spread to lung-draining lymph nodes, presumably via migrating dendritic cells. Recent work using bar-coded M. tuberculosis isolates shows that each granuloma in the lung arises from a single bacterium (Lin et al. 2014). Using PET/ CT imaging and/or necropsy, these lesions can be detected within 2-4 wk of infection in both lungs and lymph nodes, coincident with the developing adaptive immune response to the pathogen and influx of inflammatory cells (Lin et al. 2006, 2014; Rayner et al. 2013). Early lesions show some central necrosis (Lin et al. 2006) and are likely hypoxic (Via et al. 2008).

Studies in NHPs have expanded our understanding of the granuloma itself. Tuberculous granulomas are not uniform structures and, instead, display a wide variety of gross and histopathological appearances. Multiple lesion types can coexist even within the same individual. These same features can be seen in experimentally infected NHPs (Lin et al. 2009; Flynn and Klein 2011). Recently, developing lesions in infected cynomolgus macaques were tracked using FDG PET/CT imaging, and bacterial killing was assessed within each individual granuloma at necropsy (Lin et al. 2014). The physical and metabolic characteristics of individual lesions within the same animal were dynamic, followed independent trajectories, and showed a 10,000-fold range of bacterial burden. Early (4 wk) postinfection, all granulomas had culturable bacteria, but by $11 \mathrm{wk}, \sim 10 \%$ of lesions had been sterilized, and increased to $>30 \%$ by 6 mo. Strikingly, the degree of mycobacterial killing varied within lesions from the same animal regardless of whether the disease was active or latent, although there were more ster- ile lesions in latent animals (Lin et al. 2014). This study highlights the lesional heterogeneity within the same animal and suggests strongly that the ultimate outcome of infection is predicated on responses at a lesional, rather than a global level. The NHP model of TB uniquely recapitulates the spectrum of disease outcomes and granuloma characteristics observed in humans and provides an ideal platform with which to study TB pathogenesis.

\section{INVESTIGATING LATENT AND REACTIVATION TB}

In the traditional binary view of TB pathogenesis, the host can either control bacterial replication to establish a latent TB infection, or bacteria may continue to replicate and spread, resulting in active $\mathrm{TB}$ and progressive immunopathology. We now understand that TB exists as a continuous spectrum of disease states, from dormant to fulminant infection (Barry et al. 2009; Lin et al. 2009; Lin and Flynn 2010; Gideon and Flynn 2011). Where a TB patient falls along this spectrum has important implications for diagnosis, prognosis, and treatment, highlighting the importance of macaques as the only animal model that recapitulates these variable outcomes. Persons latently infected with $M$. tuberculosis are at risk for reactivation and represent a huge reservoir of potential cases of active, infectious TB. More research is needed to help better predict those most at risk for reactivation and to develop targeted therapies that may eliminate either the infection itself or the potential for reactivation. The well-characterized cynomolgus model of latent TB (Lin et al. 2009; Lin and Flynn 2010; Gideon and Flynn 2011) provides a unique opportunity to investigate important gaps in knowledge about latent M. tuberculosis infection.

The metabolic state of the bacilli during clinical latency is unknown. However, genetic mutations accumulate at the same rate in macaques with latent or active TB (Ford et al. 2011), suggesting that host bactericidal activity determines latency rather than bacterial replication rate-a hypothesis further supported by recent studies (Lin et al. 2014). PET/CT imaging of 
latently infected animals typically reveals lesions in lung-draining lymph nodes and a small number of discrete, heterogeneously FDG-avid granulomas within the lungs (J Flynn, unpubl.). As in humans, latent TB in cynomolgus macaques can be stably maintained, can spontaneously reactivate, or can reactivate in response to some immune suppression (Lin et al. 2009; Lin and Flynn 2010). TNF (tumor necrosis factor) is a key cytokine in antituberculous immunity (reviewed in O'Garra et al. 2013), and TNF neutralization in humans is associated with reactivation of latent TB (Keane 2004). Likewise, TNF blockade induces reactivation in $\sim 70 \%$ of latently infected macaques (Lin et al. 2010). This NHP model creates opportunities to investigate interventions that may reduce the reactivation risk. In one such study of prophylactic chemotherapy, a 2-mo course of metronidazole, a drug effective only in low oxygen microenvironments, was found to be as efficacious as $6 \mathrm{mo}$ of isoniazid or 2 mo of isoniazid and rifampin in preventing anti-TNF-induced reactivation (Lin et al. 2012a). In another, vaccination of macaques with a BCG/H56 heterologous primeboost regimen before low-dose infection greatly reduced the risk of reactivation following TNF neutralization (Lin et al. 2012b).

\section{MODELING HIV-TB COINFECTIONS}

The World Health Organization estimates 14 million people are coinfected with HIV and M. tuberculosis, and TB accounts for $\sim 26 \%$ of all AIDS-related deaths (WHO 2013). The magnitude of this public health problem demands urgent research into the synergy between these two pathogens and new approaches to treating coinfected individuals. Macaques are the only species besides humans susceptible to infection with both immunodeficiency virus and M. tuberculosis, making them ideal to model coinfection. Because HIV infects only humans, NHP studies use the closely related SIV or chimeric SIV-HIV (SHIV). Early investigations of mycobacterial coinfection showed that immunodeficient monkeys were susceptible to $M$. tuberculosis or even to the attenuated mycobacterial vaccine BCG (Zhou et al. 1999; Croix et al.
2000; Shen et al. 2002a; Safi et al. 2003). In fact, the susceptibility of SIV-infected macaques to mycobacterial coinfection has been used to show the safety of novel vaccines based on highly attenuated M. tuberculosis strains (Sampson et al. 2011; Jensen et al. 2012). Continued work with this model should provide insights into the mechanisms by which $M$. tuberculosis can accelerate HIV replication and hasten progression of both TB and SIV disease.

In humans, coinfection with HIV is the most powerful risk factor for reactivating latent $\mathrm{TB}$, increasing the risk of reactivation $\sim 20$-fold (Pawlowski et al. 2012). Diedrich et al. (2010) modeled this clinical scenario by using SIV to coinfect cynomolgus macaques with established latent $\mathrm{TB}$, resulting in reactivation in all macaques. Interestingly, although animals with the biggest decline in $\mathrm{CD} 4^{+} \mathrm{T}$ cell counts reactivated first, those with near-normal $\mathrm{CD}^{+}{ }^{+} \mathrm{T}$ cell counts also reactivated, albeit at later times (7-11 mo), analogous to humans coinfected with $\mathrm{HIV} / M$. tuberculosis in which reactivation $\mathrm{TB}$ can occur before $\mathrm{CD} 4^{+} \mathrm{T}$ cells decline (Lawn and Churchyard 2009). The role of $\mathrm{CD} 4^{+} \mathrm{T}$ cells in maintaining latent TB was explored further in another NHP study in which $\mathrm{CD} 4^{+} \mathrm{T}$ cells were depleted from latently infected cynomolgus macaques and reactivation occurred in only half the animals, suggesting that exacerbation of TB following HIV coinfection is not simply caused by the loss of $\mathrm{CD} 4^{+} \mathrm{T}$ cells (Lin et al. 2012c). Additional studies of macaques with latent TB suggest that SIV coinfection affects $\mathrm{CD}^{+} \mathrm{T}$ cell and monocyte function, which may be, at least in part, responsible for the TB reactivation (Mattila et al. 2011; Diedrich et al. 2013).

\section{EVALUATING NEW DRUGS AND VACCINES}

Current antimycobacterial drug regimens are lengthy-at least $6 \mathrm{mo}$ - and drug resistance continues to emerge in M. tuberculosis. New drugs that can circumvent resistance mechanisms or shorten chemotherapy courses are critically needed. Because of their relatively high throughput, small animal models of TB (e.g., mice) are often used to screen drug candidates. 
However, results in mice do not always predict drug efficacy in humans (Cynamon et al. 1999; Mitchison and Chang 2009; Williams et al. 2009; Lee et al. 2012). Furthermore, the tuberculous pathology in mice differs dramatically from that in humans. Mice do not show diverse granuloma types and do not develop cavitary diseaseall common features in human TB. Testing the most promising new chemotherapeutic agents in NHPs before advancing them into clinical trials has distinct advantages. First, drugs in NHPs display pharmacokinetics similar to those observed in humans (Lin et al. 2012a), enabling simple allometric-based dose calculations (McLeay et al. 2012). Second, cynomolgus macaques infected with $M$. tuberculosis often show a wide spectrum of lesion types including cavities (Lin et al. 2009), an important feature because it is reasonable to assume disparate drug efficacies on bacilli residing in distinct granuloma morphologies. Third, unlike humans, single-drug regimens can be tested in macaques to determine efficacy. Although NHPs are expensive to purchase and house, new advances in PET/CT imaging facilitate serial assessment of tuberculous disease before, during, and after a treatment regimen in the same animals (Lin et al. 2013). This reduces the number of animals needed. Furthermore, individual lesions can be followed by PET/CT and can be independently analyzed and considered, further enhancing the statistical power of studies with limited animals (Lin et al. 2013). A drawback to testing novel chemical compounds in large monkeys is the amount of drug that must be synthesized, often at great expense. Recently, marmosets experimentally infected with $M$. tuberculosis were shown to offer many of the same advantages of larger NHPs yet weigh $\sim 10$-fold less, making them an attractive option for testing new antimycobacterial drugs (Via et al. 2013).

An increasing number of TB vaccine candidates are available and must be down-selected to advance the most promising into clinical trials (Brennan et al. 2012; Ottenhoff and Kaufmann 2012). NHPs have long been used to test TB vaccines (Good 1968) and offer distinct advantages over other animal models. Their phylogenetic closeness to humans means they have very similar immune systems and a wealth of immunologic tools exists for studying immune responses in monkeys. Serial samples of blood and BAL (bronchoalveolar lavage) fluid can be obtained and used for immunologic assays enabling dynamic and quantitative measurements of vaccine immunogenicity. After vaccination, monkeys can be challenged with $M$. tuberculosis to assess vaccine efficacy. Because macaques can be used to model both active and latent TB, therapeutic (i.e., postinfection) vaccine regimens targeted to either disease state can be evaluated, in addition to the more conventional prophylactic (i.e., preinfection) vaccines.

Evaluating published TB vaccine studies in NHPs is confounded by multiple variables including monkey species, timing of vaccinations and challenge, route of challenge, and inoculum size. Rhesus macaques are the most commonly used species for testing TB vaccines, both historically (Barclay et al. 1970; Ribi et al. 1971; Janicki et al. 1973) and recently (Langermans et al. 2001; Sugawara et al. 2009; Verreck et al. 2009; Sharpe et al. 2010; Rahman et al. 2012), but cynomolgus macaques increasingly are being used (Langermans et al. 2001; Okada et al. 2009; Reed et al. 2009; Kita et al. 2011; Lin et al. 2012b). In the sole direct comparison study, BCG vaccination provided better protection against high-dose M. tuberculosis challenge in cynomolgus compared with rhesus macaques (Langermans et al. 2001), suggesting that rhesus were the preferred species in which to test whether a live vaccine candidate conferred better protection than BCG. However, this is contradicted by both earlier (Barclay et al. 1970; Ribi et al. 1971; Janicki et al. 1973) and more recent studies, which showed significant protection by BCG alone in rhesus (Shen et al. 2002b; Verreck et al. 2009; Sharpe et al. 2010). A wide range of challenge dose has been reported, from $3000 \mathrm{CFU}$ (Sugawara et al. 2009) to as few as $25 \mathrm{CFU}$ (Lin et al. 2012b). Too large an inoculum will overwhelm any protective effect, whereas too low a dose, especially in cynomolgus macaques, will result in latent $\mathrm{TB}$ in some control animals. In most vaccine studies, M. tuberculosis is delivered intratracheally or intrabronchially. However, aerosol challenge of 
vaccinated animals may more closely replicate natural transmission (Shen et al. 2002b; Sharpe et al. 2010). As discussed above, however, aerogenic infection may be more virulent than intrabronchial delivery and may mask subtle protective effects. The M. tuberculosis strain used to challenge vaccinated animals may affect the outcome because of differential virulence. The most commonly used challenge strains for $\mathrm{TB}$ vaccine studies are $\mathrm{H} 37 \mathrm{Rv}$ and Erdman, which do show distinct virulence profiles (see above). Clearly, a harmonized protocol for testing vaccine candidates in NHPs would be hugely beneficial, but, as yet, no consensus exists regarding these model components.

The outcome measures of protection are important considerations in NHP studies of TB vaccines or therapeutic agents. Clinical assessment (body weight, hematological parameters, and CXR) has been used during the in-life challenge phase (Verreck et al. 2009; Lin et al. 2012 b), but their predictive value has not been established. Postchallenge survival times of animals subjected to different vaccine regimens can be compared (Reed et al. 2009; Sharpe et al. 2010; Kita et al. 2011; Lin et al. 2012b). However, this poses both ethical concerns and statistical challenges, because genetic variability often results in large differences in survival times within experimental groups (Sharpe et al. 2010). Animals can be necropsied at fixed end points to compare pathology and bacterial loads between groups (Langermans et al. 2001; Okada et al. 2009; Rahman et al. 2012), but such analyses are complicated. First, the time point(s) chosen is a variable that may influence a study's conclusions. Second, the extent of pathology is difficult to quantitatively assess. Although a number of scoring systems have been developed (Lin et al. 2009; Verreck et al. 2009), there is inherent subjectivity in such analyses. Last, determining bacterial load in monkeys is technically challenging. Some researchers homogenize whole lungs for plating (Langermans et al. 2001; Verreck et al. 2009), some use a stereologic approach to guide the selection of random tissue sections for plating (Luciw et al. 2011), and some use a combination of lesion collection and random sampling (Lin et al.
2009). Many researchers report bacterial burden as CFU/gram of tissue (Langermans et al. 2001; Reed et al. 2009; Verreck et al. 2009) or CFU/ lung (Kita et al. 2011). Lin et al. devised a methodology to generate both a "CFU score" for quantitative analysis of bacterial burden and a calculable measure of bacterial dissemination (Lin et al. 2009, 2012a). However, given that the number of live bacteria within individual granulomas can vary by more than several orders of magnitude even within the same animal (Lin et al. 2014), perhaps the most accurate method to comprehensively assess bacterial burden is to use pre-necropsy imaging (e.g., PET/ CTor MRI) as a road map to identify and harvest individual lesions. These can be homogenized and plated to determine CFU/granuloma. Regions of generalized pathology (i.e., TB pneumonia or large consolidations) and the remaining grossly normal tissue can be randomly sampled (Lin et al. 2013, 2014). This methodology is less susceptible to skewing by a few granulomas that have extraordinarily high CFU. The power of this approach is increased if a portion of each lesion is subjected to quantitative PCR to enumerate $M$. tuberculosis genomes (chromosomal equivalents, or CEQ). Because mycobacterial genomes remain long after bacilli are killed (Munoz-Elias et al. 2005), CEQ reflects the cumulative number of bacteria (alive or dead) that ever existed in a particular lesion and so the $\mathrm{CFU} / \mathrm{CEQ}$ ratio reflects bacterial killing within each granuloma (Lin et al. 2014). This comprehensive approach assesses both bacterial replication and bactericidal activity for each lesion and is especially powerful in assessing vaccines or drugs, which may affect heterogenously each nidus of infection (Fig. 2).

\section{CONCLUDING REMARKS}

There is still much to learn about TB pathogenesis, and improved diagnostics, prophylactics, and therapeutics need to be developed. To take full advantage of recent advances in immunology, genomics, proteomics, metabolomics, and mathematical modeling (Marino et al. 2011), tractable animal models of $\mathrm{TB}$ that recapitulate as much as possible the features of human dis- 
C.A. Scanga and J.L. Flynn
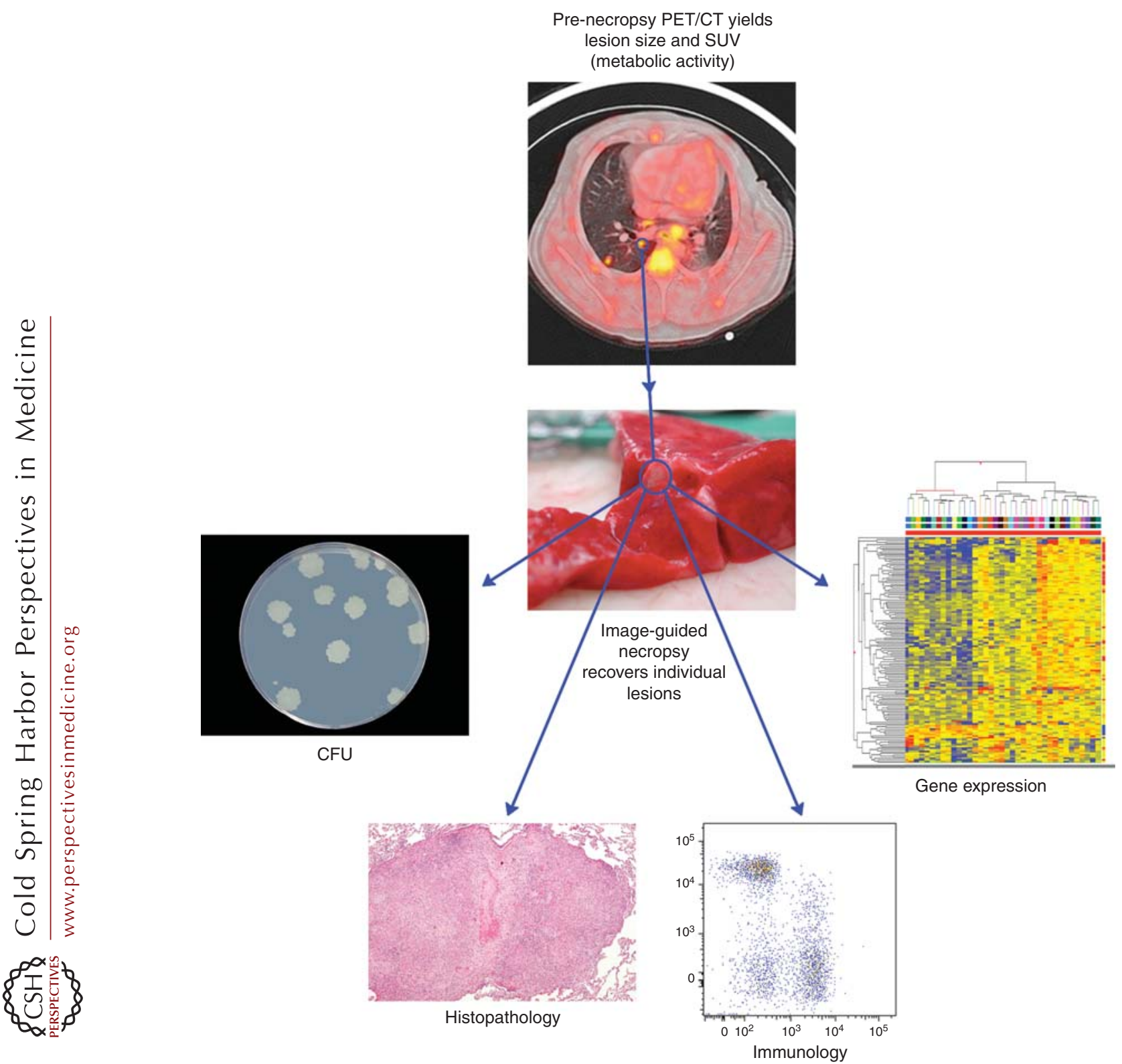

Figure 2. Modeling TB in NHPs facilitates studies based on local responses within individual lesions. Disease can be monitored over time with imaging technologies. Here, serial PET/CT imaging provides the history of a lesion, in terms of size and metabolic activity, over the course of the study. A pre-necropsy scan guides the harvesting of these individual lesions as small as $1 \mathrm{~mm}$ that can be portioned out to obtain data on bacterial load, histopathology, immunology, and gene expression. These data are distinct from global immunologic and transcriptional responses (i.e., from PBMC) and can differ from lesion-to-lesion within the same animal. SUV, standardized uptake value; CFU, colony-forming unit. (Figure credit: Chelsea L. Chedrick and Dr. Hannah P. Gideon, University of Pittsburgh.) 
ease are needed. Their phylogenetic closeness to humans, their ability to model active, latent, and reactivation $\mathrm{TB}$, and their suitability for serial sampling and imaging make NHPs an ideal experimental platform. Because of the high costs associated with purchasing and housing NHPs, particularly under ABSL-3 containment, small animal models of TB will continue to play important roles in TB research. However, NHP studies are critically important, particularly where alternative models are lacking (e.g., studies of latent TB) and to assist in selecting novel therapies or vaccines to advance into clinical trials.

\section{ACKNOWLEDGMENTS}

We gratefully acknowledge the contributions of all Flynn laboratory members, past and present; Drs. Edwin Klein and Hannah P. Gideon for supplying data for the figures; and Chelsea L. Chedrick for assistance with the figures. Our work is supported by the National Institutes of Health (grants AI50732, HL106804, EB012579, AI094745, HL110811, and AI105422), the Bill and Melinda Gates Foundation, and the Aeras Global Fund.

\section{REFERENCES}

Andersen P, Doherty TM. 2005. The success and failure of BCG-Implications for a novel tuberculosis vaccine. Nat Rev Microbiol 3: 656-662.

Baram P, Soltysik L, Condoulis W. 1971. The in vitro assay of tuberculin hypersensitivity in Macaca mulatta sensitized with bacille Calmette Guérin cell wall vaccine and-or infected with virulent Mycobacterium tuberculosis. Lab Anim Sci 21: 727-733.

Barclay WR, Anacker RL, Brehmer W, Leif W, Ribi E. 1970. Aerosol-induced tuberculosis in subhuman primates and the course of the disease after intravenous BCG vaccination. Infect Immun 2: 574-582.

Barclay WR, Busey WM, Dalgard DW, Good RC, Janicki BW, Kasik JE, Ribi E, Ulrich CE, Wolinsky E. 1973. Protection of monkeys against airborne tuberculosis by aerosol vaccination with bacillus Calmette-Guérin. Am Rev Resp Dis 107: 351-358.

Barry CE 3rd, Boshoff HI, Dartois V, Dick T, Ehrt S, Flynn J, Schnappinger D, Wilkinson RJ, Young D. 2009. The spectrum of latent tuberculosis: Rethinking the biology and intervention strategies. Nat Rev Microbiol 7: 845-855.

Benson RE, Fremming BD, Young RJ. 1955. A tuberculosis outbreak in a Macaca mulatta colony. Am Rev Tuberc 72: 204-209.
Brennan MJ, Stone MR, Evans T. 2012. A rational vaccine pipeline for tuberculosis. Int J Tuberc Lung Dis 16: 15661573.

Brok HP, Hornby RJ, Griffiths GD, Scott LA, Hart BA. 2001. An extensive monoclonal antibody panel for the phenotyping of leukocyte subsets in the common marmoset and the cotton-top tamarin. Cytometry 45: 294-303.

Budde ML, Greene JM, Chin EN, Ericsen AJ, Scarlotta M, Cain BT, Pham NH, Becker EA, Harris M, Weinfurter JT, et al. 2012. Specific $\mathrm{CD} 8^{+} \mathrm{T}$ cell responses correlate with control of simian immunodeficiency virus replication in Mauritian cynomolgus macaques. J Virol 86: 7596-7604.

Burwitz BJ, Pendley CJ, Greene JM, Detmer AM, Lhost JJ, Karl JA, Piaskowski SM, Rudersdorf RA, Wallace LT, Bimber BN, et al. 2009. Mauritian cynomolgus macaques share two exceptionally common major histocompatibility complex class I alleles that restrict simian immunodeficiency virus-specific CD8 ${ }^{+}$T cells. J Virol 83: 60116019.

Caceres N, Llopis I, Marzo E, Prats C, Vilaplana C, de Viedma DG, Samper S, Lopez D, Cardona PJ. 2012. Low dose aerosol fitness at the innate phase of murine infection better predicts virulence amongst clinical strains of $M y$ cobacterium tuberculosis. PloS ONE 7: e29010.

Capuano SV 3rd, Croix DA, Pawar S, Zinovik A, Myers A, Lin PL, Bissel S, Fuhrman C, Klein E, Flynn JL. 2003. Experimental Mycobacterium tuberculosis infection of cynomolgus macaques closely resembles the various manifestations of human M. tuberculosis infection. Infect Immun 71: 5831-5844.

Chaparas SD, Good RC, Janicki BW. 1975. Tuberculininduced lymphocyte transformation and skin reactivity in monkeys vaccinated or not vaccinated with Bacille Calmette-Guérin, then challenged with virulent $\mathrm{Myco-}$ bacterium tuberculosis. Am Rev Respir Dis 112: 43-47.

Chen CY, Huang D, Wang RC, Shen L, Zeng G, Yao S, Shen Y, Halliday L, Fortman J, McAllister M, et al. 2009. A critical role for CD8 T cells in a nonhuman primate model of tuberculosis. PLoS Pathog 5: e1000392.

Chen CY, Yao S, Huang D, Wei H, Sicard H, Zeng G, Jomaa H, Larsen MH, Jacobs WR Jr, Wang R, et al. 2013. Phosphoantigen/IL2 expansion and differentiation of $\mathrm{V} \gamma 2 \mathrm{~V} \delta 2 \mathrm{~T}$ cells increase resistance to tuberculosis in nonhuman primates. PLoS Pathog 9: e1003501.

Clark SO, Hall Y, Kelly DL, Hatch GJ, Williams A. 2011. Survival of Mycobacterium tuberculosis during experimental aerosolization and implications for aerosol challenge models. J Appl Microbiol 111: 350-359.

Corbett EL, Watt CJ, Walker N, Maher D, Williams BG, Raviglione MC, Dye C. 2003. The growing burden of tuberculosis: Global trends and interactions with the HIV epidemic. Arch Intern Med 163: 1009-1021.

Croix DA, Capuano S 3rd, Simpson L, Fallert BA, Fuller CL, Klein EC, Reinhart TA, Murphey-Corb M, Flynn JL. 2000. Effect of mycobacterial infection on virus loads and disease progression in simian immunodeficiency virus-infected rhesus monkeys. AIDS Res Hum Retrovir 16: $1895-1908$.

Cynamon MH, Klemens SP, Sharpe CA, Chase S. 1999. Activities of several novel oxazolidinones against Mycobacterium tuberculosis in a murine model. Antimicrob Agents Chemother 43: 1189-1191. 
Davis SL, Nuermberger EL, Um PK, Vidal C, Jedynak B, Pomper MG, Bishai WR, Jain SK. 2009. Noninvasive pulmonary $\left[{ }^{18} \mathrm{~F}\right]$-2-fluoro-deoxy-D-glucose positron emission tomography correlates with bactericidal activity of tuberculosis drug treatment. Antimicrob Agents Chemother 53: 4879-4884.

Diedrich CR, Mattila JT, Klein E, Janssen C, Phuah J, Sturgeon TJ, Montelaro RC, Lin PL, Flynn JL. 2010. Reactivation of latent tuberculosis in cynomolgus macaques infected with SIV is associated with early peripheral T cell depletion and not virus load. PloS ONE 5: e9611.

Diedrich CR, Mattila JT, Flynn JL. 2013. Monocyte-derived IL-5 reduces TNF production by Mycobacterium tuberculosis-specific CD4 T cells during SIV/M. tuberculosis coinfection. J Immunol 190: 6320-6328.

Fennelly KP, Jones-Lopez EC, Ayakaka I, Kim S, Menyha H, Kirenga B, Muchwa C, Joloba M, Dryden-Peterson S, Reilly N, et al. 2012. Variability of infectious aerosols produced during coughing by patients with pulmonary tuberculosis. Am J Respir Crit Care Med 186: 450-457.

Flynn JL, Klein E. 2011. Pulmonary tuberculosis in monkeys. In A color atlas of comparative pulmonary tuberculosis histopathology (ed. Leong VDJ, Dick T), pp. 83-106. CRC, Boca Raton, FL.

Flynn JL, Tsenova L, Izzo A, Kaplan G. 2008. Experimental animal models of tuberculosis. In Handbook of tuberculosis: Immunology and cell biology (ed. Kaufmann SHE, Britton WJ), pp. 389-417. Wiley-VCH, Weinheim, Germany.

Ford CB, Lin PL, Chase MR, Shah RR, Iartchouk O, Galagan J, Mohaideen N, Ioerger TR, Sacchettini JC, Lipsitch M, et al. 2011. Use of whole genome sequencing to estimate the mutation rate of Mycobacterium tuberculosis during latent infection. Nat Genet 43: 482-486.

Fourie PB, Odendaal MW. 1983. Mycobacterium tuberculosis in a closed colony of baboons (Papio ursinus). Lab Anim 17: $125-128$.

Gideon HP, Flynn JL. 2011. Latent tuberculosis: What the host "sees"? Immunol Res 50: 202-212.

Good RC. 1968. Biology of the mycobacterioses. Simian tuberculosis: Immunologic aspects. Ann NY Acad Sci 154: $200-213$

Good RC. 1984. Diseases in nonhuman primates. In The mycobacteria: A sourcebook (ed. Kubica GP, Wayne LG), pp. 903-921. Dekker, New York.

Gormus BJ, Blanchard JL, Alvarez XH, Didier PJ. 2004. Evidence for a rhesus monkey model of asymptomatic tuberculosis. J Med Primatol 33: 134-145.

Janicki BW, Good RC, Minden P, Affronti LF, Hymes WF. 1973. Immune responses in rhesus monkeys after bacillus Calmette-Guérin vaccination and aerosol challenge with Mycobacterium tuberculosis. Am Rev Respir Dis 107: 359366.

Jensen K, Ranganathan UD, Van Rompay KK, Canfield DR, Khan I, Ravindran R, Luciw PA, Jacobs WR Jr, Fennelly G, Larsen MH, et al. 2012. A recombinant attenuated Mycobacterium tuberculosis vaccine strain is safe in immunosuppressed simian immunodeficiency virus-infected infant macaques. Clin Vac Immunol 19: 1170-1181.

Keane J. 2004. Tumor necrosis factor blockers and reactivation of latent tuberculosis. Clin Infect Dis 39: 300-302.
Keet DF, Kriek NP, Bengis RG, Grobler DG, Michel A. 2000. The rise and fall of tuberculosis in a free-ranging chacma baboon troop in the Kruger National Park. Onderstepoort $J$ Vet Res 67: 115-122.

Kita Y, Okada M, Nakajima T, Kanamaru N, Hashimoto S, Nagasawa T, Kaneda Y, Yoshida S, Nishida Y, Nakatani H, et al. 2011. Development of therapeutic and prophylactic vaccine against tuberculosis using monkey and transgenic mice models. Hum Vaccin 7: 108-114.

Krebs KC, Jin Z, Rudersdorf R, Hughes AL, O'Connor DH. 2005. Unusually high frequency MHC class I alleles in Mauritian origin cynomolgus macaques. J Immunol 175: 5230-5239.

Langermans JA, Andersen P, van Soolingen D, Vervenne RA, Frost PA, van der Laan T, van Pinxteren LA, van den Hombergh J, Kroon S, Peekel I, et al. 2001. Divergent effect of bacillus Calmette-Guérin (BCG) vaccination on Mycobacterium tuberculosis infection in highly related macaque species: Implications for primate models in tuberculosis vaccine research. Proc Natl Acad Sci 98: 11497-11502.

Lawn SD, Churchyard G. 2009. Epidemiology of HIV-associated tuberculosis. Curr Opin HIVAIDS 4: 325-333.

Lee M, Lee J, Carroll MW, Choi H, Min S, Song T, Via LE, Goldfeder LC, Kang E, Jin B, et al. 2012. Linezolid for treatment of chronic extensively drug-resistant tuberculosis. New Engl J Med 367: 1508-1518.

Lewinsohn DM, Tydeman IS, Frieder M, Grotzke JE, Lines RA, Ahmed S, Prongay KD, Primack SL, Colgin LM, Lewis AD, et al. 2006. High resolution radiographic and fine immunologic definition of TB disease progression in the rhesus macaque. Microbes Infect 8: 2587-2598.

Lin PL, Flynn JL. 2010. Understanding latent tuberculosis: A moving target. J Immunol 185: 15-22.

Lin PL, Pawar S, Myers A, Pegu A, Fuhrman C, Reinhart TA, Capuano SV, Klein E, Flynn JL. 2006. Early events in Mycobacterium tuberculosis infection in cynomolgus macaques. Infect Immun 74: 3790-3803.

Lin PL, Rodgers M, Smith L, Bigbee M, Myers A, Bigbee C, Chiosea I, Capuano SV, Fuhrman C, Klein E, et al. 2009. Quantitative comparison of active and latent tuberculosis in the cynomolgus macaque model. Infect Immun 77: 4631-4642.

Lin PL, Myers A, Smith L, Bigbee C, Bigbee M, Fuhrman C, Grieser H, Chiosea I, Voitenek NN, Capuano SV, et al. 2010. Tumor necrosis factor neutralization results in disseminated disease in acute and latent Mycobacterium tuberculosis infection with normal granuloma structure in a cynomolgus macaque model. Arthritis Rheum 62: 340350.

Lin PL, Dartois V, Johnston PJ, Janssen C, Via L, Goodwin MB, Klein E, Barry CE III, Flynn JL. 2012a. Metronidazole prevents reactivation of latent Mycobacterium tuberculosis infection in macaques. Proc Natl Acad Sci 109: 14188-14193.

Lin PL, Dietrich J, Tan E, Abalos RM, Burgos J, Bigbee C, Bigbee M, Milk L, Gideon HP, Rodgers M, et al. 2012b. The multistage vaccine $\mathrm{H} 56$ boosts the effects of BCG to protect cynomolgus macaques against active tuberculosis and reactivation of latent Mycobacterium tuberculosis infection. J Clin Invest 122: 303-314. 
Lin PL, Rutledge T, Green AM, Bigbee M, Fuhrman C, Klein E, Flynn JL. 2012c. CD4 T cell depletion exacerbates acute Mycobacterium tuberculosis while reactivation of latent infection is dependent on severity of tissue depletion in cynomolgus macaques. AIDS Res Hum Retrovir 28: 1693-1702.

Lin PL, Coleman T, Carney JP, Lopresti BJ, Tomko J, Fillmore D, Dartois V, Scanga C, Frye LJ, Janssen C, et al. 2013. Radiologic responses in cynomolgous macaques for assessing tuberculosis chemotherapy regimens. Antimicrob Agents Chemother 57: 4237-4244.

Lin PL, Ford CB, Coleman MT, Myers AJ, Gawande R, Ioerger T, Sacchettini J, Fortune SM, Flynn JL. 2014. Sterilization of granulomas is common in active and latent tuberculosis despite within-host variability in bacterial killing. Nat Med 20: 75-79.

Luciw PA, Oslund KL, Yang XW, Adamson L, Ravindran R, Canfield DR, Tarara R, Hirst L, Christensen M, Lerche NW, et al. 2011. Stereological analysis of bacterial load and lung lesions in nonhuman primates (rhesus macaques) experimentally infected with Mycobacterium tuberculosis. Am J Physiol Lung Cell Mol Physiol 301: L731L738.

Manca C, Tsenova L, Barry CE III, Bergtold A, Freeman S, Haslett PA, Musser JM, Freedman VH, Kaplan G. 1999. Mycobacterium tuberculosis CDC1551 induces a more vigorous host response in vivo and in vitro, but is not more virulent than other clinical isolates. J Immunol 162: 6740-6746.

Marino S, Linderman JJ, Kirschner DE. 2011. A multifaceted approach to modeling the immune response in tuberculosis. Wiley Interdiscip Rev Syst Biol Med 3: 479489.

Mattila JT, Diedrich CR, Lin PL, Phuah J, Flynn JL. 2011. Simian immunodeficiency virus-induced changes in $\mathrm{T}$ cell cytokine responses in cynomolgus macaques with latent Mycobacterium tuberculosis infection are associated with timing of reactivation. J Immunol 186: 3527-3537.

Mayhall CG, Lamb VA, Coleman PH. 1981. Infection in rhesus (Macaca mulatta) and squirrel (Saimiri sciureus) monkeys due to Mycobacterium tuberculosis phage type B. Outbreak in a primate colony. J Med Primatol 10:302311.

McLeay SC, Morrish GA, Kirkpatrick CM, Green B. 2012. The relationship between drug clearance and body size: Systematic review and meta-analysis of the literature published from 2000 to 2007. Clin Pharmacokinet 51: 319330.

Mehra S, Golden NA, Dutta NK, Midkiff CC, Alvarez X, Doyle LA, Asher M, Russell-Lodrigue K, Monjure C, Roy CJ, et al. 2011. Reactivation of latent tuberculosis in rhesus macaques by coinfection with simian immunodeficiency virus. J Med Primatol 40: 233-243.

Michel AL, Hlokwe TM, Espie IW, van Zijll Langhout M, Koeppel K, Lane E. 2013. Mycobacterium tuberculosis at the human/wildlife interface in a high TB burden country. Transbound Emerg Dis 60: 46-52.

Min F, Zhang Y, Pan J, Wang J, Yuan W. 2013. Mycobacterium tuberculosis infection in rhesus monkeys (Macaca mulatta) and evaluation of ESAT- 6 and CFP10 as immunodiagnostic antigens. Exp Anim 62: 281-293.
Mitchison DA, Chang KC. 2009. Experimental models of tuberculosis: Can we trust the mouse? Am J Respir Crit Care Med 180: 201-202.

Montali RJ, Mikota SK, Cheng LI. 2001. Mycobacterium tuberculosis in zoo and wildlife species. Rev Sci Tech 20: 291-303.

Motzel SL, Schachner RD, Kornegay RW, Fletcher MA, Kanaya B, Gomez JA, Ngai DT-W, Pouch WJ, Washington MV, Handt LA, et al. 2003. Diagnosis of tuberculosis in nonhuman primates. In International perspectives: The future of nonhuman primate resources, pp. 156-159. National Academies Press, Washington, DC.

Munoz-Elias EJ, Timm J, Botha T, Chan WT, Gomez JE, McKinney JD. 2005. Replication dynamics of Mycobacterium tuberculosis in chronically infected mice. Infect Immun 73: 546-551.

O'Garra A, Redford PS, McNab FW, Bloom CI, Wilkinson RJ, Berry MP. 2013. The immune response in tuberculosis. Ann Rev Immunol 31: 475-527.

Okada M, Kita Y, Nakajima T, Kanamaru N, Hashimoto S, Nagasawa T, Kaneda Y, Yoshida S, Nishida Y, Nakatani H, et al. 2009. Novel prophylactic and therapeutic vaccine against tuberculosis. Vaccine 27: 3267-3270.

Ottenhoff TH, Kaufmann SH. 2012. Vaccines against tuberculosis: Where are we and where do we need to go? PLoS Pathog 8: e1002607.

Palanisamy GS, Smith EE, Shanley CA, Ordway DJ, Orme IM, Basaraba RJ. 2008. Disseminated disease severity as a measure of virulence of Mycobacterium tuberculosis in the guinea pig model. Tuberculosis 88: 295-306.

Panarella ML, Bimes RS. 2010. A naturally occurring outbreak of tuberculosis in a group of imported cynomolgus monkeys (Macaca fascicularis). J Am Assoc Lab Anim Sci 49: $221-225$.

Pawlowski A, Jansson M, Skold M, Rottenberg ME, Kallenius G. 2012. Tuberculosis and HIV co-infection. PLoS Pathog 8: e1002464.

Payne KS, Novak JJ, Jongsakul K, Imerbsin R, Apisitsaowapa Y, Pavlin JA, Hinds SB. 2011. Mycobacterium tuberculosis infection in a closed colony of rhesus macaques (Macaca mulatta). J Am Assoc Lab Anim Sci 50: 105-108.

Rahman S, Magalhaes I, Rahman J, Ahmed RK, Sizemore DR, Scanga CA, Weichold F, Verreck F, Kondova I, Sadoff $\mathrm{J}$, et al. 2012. Prime-boost vaccination with $\mathrm{rBCG} / \mathrm{rAd} 35$ enhances $\mathrm{CD}^{+}{ }^{+}$cytolytic T-cell responses in lesions from Mycobacterium tuberculosis-infected primates. Mol Med 18: $647-658$.

Rayner EL, Pearson GR, Hall GA, Basaraba RJ, Gleeson F, McIntyre A, Clark S, Williams A, Dennis MJ, Sharpe SA. 2013. Early lesions following aerosol infection of rhesus macaques (Macaca mulatta) with Mycobacterium tuberculosis strain H37RV. J Comp Pathol 149: 475-485.

Reed SG, Coler RN, Dalemans W, Tan EV, DeLa Cruz EC, Basaraba RJ, Orme IM, Skeiky YA, Alderson MR, Cowgill KD, et al. 2009. Defined tuberculosis vaccine, Mtb72F/ AS02A, evidence of protection in cynomolgus monkeys. Proc Natl Acad Sci 106: 2301-2306.

Ribi E, Anacker RL, Barclay WR, Brehmer W, Harris SC, Leif WR, Simmons J. 1971. Efficacy of mycobacterial cell walls as a vaccine against airborne tuberculosis in the Rheusus monkey. J Infect Dis 123: 527-538. 
Safi H, Gormus BJ, Didier PJ, Blanchard JL, Lakey DL, Martin LN, Murphey-Corb M, Vankayalapati R, Barnes PF. 2003. Spectrum of manifestations of Mycobacterium tuberculosis infection in primates infected with SIV. AIDS Res Hum Retroviruses 19: 585-595.

Sampson SL, Mansfield KG, Carville A, Magee DM, Quitugua T, Howerth EW, Bloom BR, Hondalus MK. 2011 Extended safety and efficacy studies of a live attenuated double leucine and pantothenate auxotroph of Mycobacterium tuberculosis as a vaccine candidate. Vaccine 29: 4839-4847.

Schmidt LH. 1956. Some observations on the utility of simian pulmonary tuberculosis in defining the therapeutic potentialities of isoniazid. Am Rev Tuberc 74: 138-153; discussion, 153-159.

Schmidt LH. 1966. Studies on the antituberculous activity of ethambutol in monkeys. Ann NY Acad Sci 135: 747758.

Schmidt L, Grover A, Hoffmann R. 1959. The comparative therapeutic activities of thiocarbanidin and para-aminosalicylic acid administered alone and in combination with isoniazid. Trans 18th VA-Armed Forces Conf Chemother Tuberculosis 312-317.

Schroeder CR. 1938. Acquired tuberculosis in the primate in laboratories and zoological collections. Am J Pub Health Nations Health 28: 469-475.

Sharpe SA, Eschelbach E, Basaraba RJ, Gleeson F, Hall GA, McIntyre A, Williams A, Kraft SL, Clark S, Gooch K, et al. 2009. Determination of lesion volume by MRI and stereology in a macaque model of tuberculosis. Tuberculosis 89: 405-416.

Sharpe SA, McShane H, Dennis MJ, Basaraba RJ, Gleeson F, Hall G, McIntyre A, Gooch K, Clark S, Beveridge NE, et al. 2010. Establishment of an aerosol challenge model of tuberculosis in rhesus macaques and an evaluation of endpoints for vaccine testing. Clin Vaccine Immunol 17: $1170-1182$.

Shen Y, Zhou D, Chalifoux L, Shen L, Simon M, Zeng X, Lai X, Li Y, Sehgal P, Letvin NL, et al. 2002a. Induction of an AIDS virus-related tuberculosis-like disease in macaques: A model of simian immunodeficiency virus-mycobacterium coinfection. Infect Immun 70: 869-877.

Shen Y, Zhou D, Qiu L, Lai X, Simon M, Shen L, Kou Z, Wang Q, Jiang L, Estep J, et al. 2002b. Adaptive immune response of $\mathrm{V} \gamma 2 \mathrm{~V} \delta 2^{+} \mathrm{T}$ cells during mycobacterial infections. Science 295: 2255-2258.

Shin NS, Kwon SW, Han DH, Bai GH, Yoon J, Cheon DS, Son YS, Ahn K, Chae C, Lee YS. 1995. Mycobacterium tuberculosis infection in an orangutan (Pongo pygmaeus). The J Vet Med Sci 57: 951-953.

Sugawara I, Sun L, Mizuno S, Taniyama T. 2009. Protective efficacy of recombinant BCG Tokyo (Ag85A) in rhesus monkeys (Macaca mulatta) infected intratracheally with H37Rv Mycobacterium tuberculosis. Tuberculosis 89: 62-67.

Tsenova L, Ellison E, Harbacheuski R, Moreira AL, Kurepina N, Reed MB, Mathema B, Barry CE 3rd, Kaplan G. 2005. Virulence of selected Mycobacterium tuberculosis clinical isolates in the rabbit model of meningitis is dependent on phenolic glycolipid produced by the bacilli. J Infect Dis 192: $98-106$.

Verreck FA, Vervenne RA, Kondova I, van Kralingen KW, Remarque EJ, Braskamp G, van der Werff NM, Kersbergen A, Ottenhoff TH, Heidt PJ, et al. 2009. MVA.85A boosting of BCG and an attenuated, phoP deficient $M$. tuberculosis vaccine both show protective efficacy against tuberculosis in rhesus macaques. PloS ONE 4: e5264.

Via LE, Lin PL, Ray SM, Carrillo J, Allen SS, Eum SY, Taylor K, Klein E, Manjunatha U, Gonzales J, et al. 2008. Tuberculous granulomas are hypoxic in guinea pigs, rabbits, and nonhuman primates. Infect Immun 76: 2333-2340.

Via LE, Schimel D, Weiner DM, Dartois V, Dayao E, Cai Y, Yoon YS, Dreher MR, Kastenmayer RJ, Laymon CM, et al. 2012. Infection dynamics and response to chemotherapy in a rabbit model of tuberculosis using $\left[{ }^{18} \mathrm{~F}\right] 2$-fluorodeoxy-D-glucose positron emission tomography and computed tomography. Antimicrob Agents Chemother 56: 4391-4402.

Via LE, Weiner DM, Schimel D, Lin PL, Dayao E, Tankersley SL, Cai Y, Coleman MT, Tomko J, Paripati P, et al. 2013. Differential virulence and disease progression following Mycobacterium tuberculosis complex infection of the common marmoset (Callithrix jacchus). Infect Immun 81: 2909-2919.

Walsh GP, Tan EV, dela CruzEC, Abalos RM, Villahermosa LG, Young LJ, Cellona RV, Nazareno JB, Horwitz MA. 1996. The Philippine cynomolgus monkey (Macaca fasicularis) provides a new nonhuman primate model of tuberculosis that resembles human disease. Nat Med 2: 430-436.

Wei H, Wang R, Yuan Z, Chen CY, Huang D, Halliday L, Zhong W, Zeng G, Shen Y, Shen L, et al. 2009. DR*W201/ P65 tetramer visualization of epitope-specific CD4 T-cell during $M$. tuberculosis infection and its resting memory pool after BCG vaccination. PloS ONE 4: e6905.

WHO. 2013. Global tuberculosis report 2013. World Health Organization, http://www.who.int/tb/publications/ global_report/en/.

Williams KN, Stover CK, Zhu T, Tasneen R, Tyagi S, Grosset JH, Nuermberger E. 2009. Promising antituberculosis activity of the oxazolidinone PNU-100480 relative to that of linezolid in a murine model. Antimicrob Agents Chemother 53: 1314-1319.

Yan G, Zhang G, Fang X, Zhang Y, Li C, Ling F, Cooper DN, Li Q, Li Y, van Gool AJ, et al. 2011. Genome sequencing and comparison of two nonhuman primate animal models, the cynomolgus and Chinese rhesus macaques. Nat Biotechnol 29: 1019-1023.

Zhang J, Ye YQ, Wang Y, Mo PZ, Xian QY, Rao Y, Bao R, Dai M, Liu JY, Guo M, et al. 2011. M. tuberculosis H37Rv infection of Chinese rhesus macaques. J Neuroimmune Pharmacol 6: 362-370.

Zhou D, Shen Y, Chalifoux L, Lee-Parritz D, Simon M, Sehgal PK, Zheng L, Halloran M, Chen ZW. 1999. Mycobacterium bovis bacille Calmette-Guérin enhances pathogenicity of simian immunodeficiency virus infection and accelerates progression to AIDS in macaques: A role of persistent T cell activation in AIDS pathogenesis. J Immunol 162: 2204-2216. 


\section{$\&_{\mathrm{CSH}}^{\infty} \&$ Cold Spring Harbor

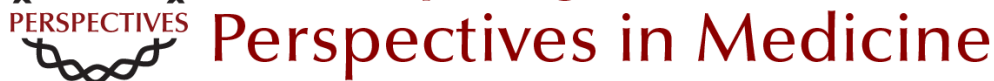

\section{Modeling Tuberculosis in Nonhuman Primates}

Charles A. Scanga and JoAnne L. Flynn

Cold Spring Harb Perspect Med 2014; doi: 10.1101/cshperspect.a018564 originally published online September 11, 2014

\section{Subject Collection Tuberculosis}

Transmission and Institutional Infection Control of Tuberculosis Edward A. Nardell

Innate and Adaptive Cellular Immune Responses

to Mycobacterium tuberculosis Infection Katrin D. Mayer-Barber and Daniel L. Barber

Tuberculosis Comorbidity with Communicable and Noncommunicable Diseases

Matthew Bates, Ben J. Marais and Alimuddin Zumla

Host-Directed Therapies for Tuberculosis David M. Tobin

Immunity and Immunopathology in the

Tuberculous Granuloma

Antonio J. Pagán and Lalita Ramakrishnan

Tuberculosis Drug Development: History and

Evolution of the Mechanism-Based Paradigm? Sumit Chakraborty and Kyu Y. Rhee

Genetic Approaches to Facilitate Antibacterial

Drug Development

Dirk Schnappinger

The Tuberculosis Drug Discovery and

Development Pipeline and Emerging Drug Targets

Khisimuzi Mdluli, Takushi Kaneko and Anna Upton
Clinical Aspects of Adult Tuberculosis Robert Loddenkemper, Marc Lipman and Alimuddin Zumla

Advances in Diagnostic Assays for Tuberculosis Stephen D. Lawn

Diagnosis and Management of Latent

Tuberculosis Infection

Laura Muñoz, Helen R. Stagg and Ibrahim

Abubakar

Mycobacterial Growth

Iria Uhía, Kerstin J. Williams, Vahid Shahrezaei, et al.

Multidrug-Resistant Tuberculosis and Extensively

Drug-Resistant Tuberculosis

Kwonjune J. Seung, Salmaan Keshavjee and Michael L. Rich

The Mycobacterial Cell Wall--Peptidoglycan and

Arabinogalactan Luke J. Alderwick, James Harrison, Georgina S. Lloyd, et al.

Tuberculosis and HIV Coinfection Judith Bruchfeld, Margarida Correia-Neves and Gunilla Källenius

Imaging in Tuberculosis Jamshed B. Bomanji, Narainder Gupta, Parveen Gulati, et al.

For additional articles in this collection, see http://perspectivesinmedicine.cshlp.org/cgi/collection/ 